\title{
ERP Software as Service (SaaS): Factors Affecting Adoption in South Africa
}

\author{
Motheo Lechesa ${ }^{1}$, Lisa Seymour ${ }^{1}$, and Joachim Schuler ${ }^{2}$ \\ ${ }^{1}$ Information Systems Department, University of Cape Town, Private Bag, \\ Rondebosch 7700, South Africa \\ ${ }^{2}$ Pforzheim University, Tiefenbronnerstrasse 65, \\ 75175 Pforzheim, Germany \\ Lisa.Seymour@uct.ac.za, Joachim.Schuler@hs-pforzheim.de
}

\begin{abstract}
Within the cloud computing hype, ERP SaaS is receiving more focus from ERP vendors such as ERP market leader SAP announcing SAP by Design, their new ERP SaaS solution. SaaS is a new approach to deliver software and has had proven success with CRM systems such as Salesforce.com. The appeal of SaaS is driven by amongst other things, lower Total Cost of Ownership and faster implementation periods. However, the rate at which ERP SaaS is being adopted is low in comparison to other SaaS applications such as CRM or Human Resource systems. Hence the need to establish the reasons for this low adoption. Consequently the purpose of this research was to determine barriers that affect the adoption of ERP SaaS in South Africa. Using interviews and qualitative data analysis, this study developed a model that explains the factors that affect the adoption of ERP SaaS. Network limitations, customisation, security and cost concerns were raised as dominant factors affecting the adoption of ERP SaaS. The research concludes by suggesting that over time the adoption of ERP SaaS should increase as the technology matures.
\end{abstract}

Keywords: ERP adoption, SaaS, South Africa, cloud computing.

\section{$1 \quad$ Introduction}

Enterprise Resource Planning (ERP) Systems have been adopted by many organisations as a way to improve efficiency and to achieve strategic goals set by management [1]. The major benefit associated with ERP systems is their ability to integrate organisational data and processes to achieve improved efficiency and productivity levels [2]. Despite their usefulness, ERP system implementations are associated with high implementation costs driven by the cost of hardware, software and consultancy as well as high maintenance costs [1],[2].

As organisations continue to seek ways to reduce costs and utilise available technology to achieve desired objectives, alternative ways of implementing ERP systems have had to be explored [3]. In particular, the Software as a Service (SaaS) model has emerged as a real alternative to implementing in-house ERP systems. ERP 
SaaS has been implemented successfully in Europe, some parts of North America and in Asia Pacific Countries [4].

The major benefit of ERP SaaS is low implementation costs and a flexible pricing model that does not require a major capital outlay. However, in comparison to other SaaS applications, the rate at which ERP SaaS is being adopted is low [5]. The reason for slow adoption of ERP SaaS varies from issues around security and customisation to integration and other concerns [6].

The purpose of this paper is to determine factors that affect the adoption of ERP SaaS in South Africa. This paper should be useful to potential clients of ERP SaaS, to assess the factors that they should consider in deciding whether to adopt ERP SaaS or not. For Vendors, this paper shall provide an understanding of the factors that their clients consider in making decisions about whether to adopt ERP SaaS or not. This work also contributes to the research domain by providing issues central to ERP SaaS adoption.

\section{Literature Review}

\subsection{Software as a Service}

Software as a Service (SaaS) is explained as a business model that allows the vendor to manage software and deliver it as a service over the internet [7]. SaaS first came into the scene in the late 1990s when discussions about turning software into a service emerged and Salesforce.com launched CRM SaaS [8]. The SaaS architecture is multitenant based with SaaS application vendors owning and maintaining it [9],[7]. Contrary to the ASP model, SaaS provides a much better value creation through resource sharing, standardisation of processes and centralised data.

The National Institute of Standards and Technology (NIST) and Cloud Security Alliance (CSA) have described cloud computing as "a model for enabling convenient, on demand network access to a shared pool of configurable computing resources that can be rapidly provisioned and released with minimal management effort or service vendor interaction" [10]. The cloud model incorporates Software as a Service (SaaS), Platform as a Service (PaaS) and Infrastructure as a Service (IaaS) [10],[11].

As technology involved in cloud computing matures, SaaS continues to attract interest across a broad spectrum of stakeholders and is gaining momentum across a spectrum of applications. The vendor and the user alike benefit from the adoption of SaaS [12]. On the part of the vendor, SaaS reduces the maintenance and upgrading costs of the system [13]. In addition, SaaS vendors gain competitive edge over other software vendors since they provide faster upgrades and patches [13].

On the part of the Clients, a SaaS application allows a software implementation project to be started on a pay-as-you go basis, scaling on business needs. This saves in upfront costs because payments for software and hardware are paid over a period of time [14]. So, SaaS helps to focus on the core areas of the business without too much concern on information technology issues [8]. SaaS implementations are also shorter compared to installed applications [13]. 


\subsection{ERP SaaS}

ERP SaaS means, to deliver an ERP system "as a service", not as in the past, where ERP systems had been implemented "on premise" as products bought by clients. The most important disparities between ERP SaaS and installed in-house ERP applications are, that ERP SaaS is accessed through the internet, the application and data are under control of the service provider while installed applications are offered as a product and accessed and controlled from the customer's location. Moreover, the payment for the software services is provided through subscriptions that have to be paid e.g. per user on a monthly basis [14].

Although ERP SaaS has been implemented in Europe and in the United States of America (USA), the rate at which it is being adopted is lower in comparison to other software applications such as CRM and Human capital management (HCM) [15]. The reason for this slow adoption is the fact that most organisations are not yet ready to trust the SaaS model with business, critical or core applications.

An Aberdeen Group survey [16]carried out on over 1200 companies operating mainly in Europe found ERP SaaS deployments to be less prevalent compared to other SaaS deployments. Although ERP is lagging behind other applications in terms of SaaS based applications there seems to be a general consensus that ERP SaaS is gaining momentum [17]. To increase the adoption rate of ERP SaaS, issues impeding its adoption need be addressed.

\subsection{Barriers to Adoption of ERP SaaS}

In general the issues that negatively impact on the adoption of ERP SaaS model are similar to concerns raised for adopting cloud computing. These issues include security and privacy, support, interoperability and compliance as well as loss of control over data and other computing resources [18].

Customisation. Although SaaS is implemented in a quicker and easier manner than "on-premise", in most cases, it does so at the expense of configuration and customisation, thereby losing flexibility [19],[7]. A balance needs to be maintained when it comes to customisation and configuration of SaaS products for both the vendor and the client. Flexibility is necessary as an ERP SaaS system or any system for that matter may require some kind of configuration or customisation in order to address or cater for the unique aspects of the adopting organisation [4]. Hence, the SaaS architecture should support configurability because it is a crucial requirement for clients in order to differentiate their business from competition [20]. Otherwise, the SaaS model may experience a low adoption rate [20]. Hence there is a challenge for vendors to offer ERP SaaS solutions capable of delivering customisable source code for more complex ERP systems [4].

Security and Privacy. Security is always an issue when it comes to any software implementation [10]. Concerns over security have been raised as a concern with the SaaS model with many potential clients reticent to trust third parties with their data, 
especially sensitive corporate data [21]. Yet, [21] argue that there is no reason why services over the cloud can't be as secure as those provided by in-house IT.

Cost. The issue of ERP SaaS cost is twofold, being the once off implementation cost and the annual subscription [22]. The implementation cost of ERP SaaS may include initial consulting and configuration costs, while on-going subscriptions costs includes hardware, software and support personnel [22]. The most appealing SaaS feature is the lower total cost of ownership (TCO), with the majority of articles referring to SaaS benefits mentioning the lower TCO. Burrel [6] mentioned that "SaaS has been touted to major organisations as the new cure-all that solves the CIO's cost enigma at a stroke by significantly reducing implementation costs, outsourcing developments, slashing consultancy costs and devolving infrastructure maintenance and servicing".

Regulation. The legal framework in the form of legislation and standards within which organisations operate has become very stringent [23]. In this respect legal issues about data protection, confidentiality, copyright, audit and controls should be considered by both the potential user and vendors alike [24]. In particular the enterprise clients need to ensure that the technology they adopt satisfies the legal requirements in terms of the data it provides [18]. An example is legal requirements in many countries prohibiting SaaS vendors from keeping customer data and copyright material outside the national boundaries within which those clients reside, such as the USA Patriot Act [21].

Network Limitations. Linked with the network limitation is the availability of system concern. Often organisations would require a $100 \%$ availability of systems especially those such as ERP systems that are considered critical [18]. To ensure that the ERP system itself and the network provides $100 \%$ availability or very close to that, it is vitally important that service level agreements (SLA) are entered into between the vendors and the clients [18].

Application and Organisation Specific Issues. Drivers of SaaS vary depending on the characteristics of the application that is considered for SaaS outsourcing. Since ERP systems possess strategic significance for organisations and are not highly standardised, they rank among the applications with the lowest SaaS adoption rates [5]. Furthermore, there are some organisations for which, because of their nature, SaaS is not well suited [25]. For instance, organisations which base their survival on maintaining secret or confidential data are more likely not to adapt SaaS. Therefore the speed at which ERP SaaS is adopted may differ depending on the nature of the organisation or industry.

Integration. The integration of SaaS applications with other in-house application or other SaaS vendors is still a big challenge to the extent that the cost of integration can be $30-45 \%$ of the overall SaaS implementation [12]. Another aspect of the issue 
around integration relates to the fact there are no interoperability standards within the cloud computing arena which creates a possible lock-in scenario for the clients [26] where they are not able to use integrated SaaS applications provided and supported by distinctive vendors, as the two solutions would not be interoperable [4]. This emphasises the importance for vendors to design and develop SaaS integration by first reviewing business processes, integration design and implementation, data migration, testing, production and monitoring; and then figuring areas where integration may be a concern with the aim of addressing deficiencies[12],[19]. Integration as a service solutions are beginning to find ways of simplifying integration issue on a cloudto-cloud platform while SaaS vendors are addressing in house integration issues by pre-building integration within the SaaS solution with the aim of reducing complexity and cost [12].

Summary of Barriers. The reviewed literature suggests that ERP SaaS is an attractive solution for organisations that have insufficient resources to consider onpremise ERP adoption. Yet there is limited research into SAAS ERP and adoption has been slow. A review of the literature identified that the major barriers to adoption of SaaS applications include concerns around security and privacy; regulatory compliance; limited customisation; network limitations; cost clarity; integration concerns; and application and organisation specific issues. However, due to a lack of empirical research it is not known whether these adoption concerns are valid for SaaS ERP. Also there seems to be a lack of frameworks or theory supporting these concerns. Hence, the need for more understanding and this research.

\subsection{Research Framework}

The purpose of this research was to study the factors that affect adoption. The Technology-Environment-Organisation (TOE) framework was considered as the most appropriate theoretical model for the purpose of this research. The framework is an institutional theory that has been widely used for the adoption of complex innovations such as e.g. e-businesses [27]. It focuses on three main characteristics associated with technology innovation namely technology, organisation and environment. The use of TOE is suitable for technology innovations that are associated with uncertainties regarding the current and future status of that technology innovation [28].

\section{The Context: SaaS in South Africa}

ERP adoption is arguably more of a challenge for organisations in developing countries such as South Africa, given the high cost of capital and the shortages of IT skills. Hence the SaaS model does appear to address many adoption barriers. While a number of articles has been written in South Africa about cloud computing and ERP SaaS, there is limited literature from credible sources about it. There are articles that are intermittently posted on web sites about cloud computing, in particular ITweb has a number of articles. A survey was carried out in 2009 by Fujutsi Technology 
Solutions that revealed that organisations in South Africa are aware of cloud computing [29]. The survey revealed that in South Africa, the value of cloud computing is not clear, and where the value was clear it was by hampered by the required networking infrastructure [29].

\section{$4 \quad$ Research Method}

The research followed an interpretive philosophy [30] to gain a deep understanding of factors affecting ERP SaaS adoption in South Africa. Qualitative primary interview data was collected from individuals with the required knowledge and experience. Purposive sampling was used to select participants from five South African organisations. All participants had experience of a minimum of 10 years in the Information, Communication and Technology (ICT) industry. Ethical clearance for the research was obtained from the university, participants signed to indicate interview consent and their anonymity was assured. Table 1 summarises the participant's details, their experience, type of industry and other relevant information.

Table 1. Research Participants

\begin{tabular}{|l|l|l|l|l|}
\hline $\begin{array}{l}\text { Interviewee } \\
\text { Position }\end{array}$ & $\begin{array}{l}\text { ICT } \\
\text { Experience } \\
\text { in IT-Years }\end{array}$ & $\begin{array}{l}\text { Industry } \\
\text { Sector }\end{array}$ & $\begin{array}{l}\text { Size in terms of } \\
\text { \# employees }\end{array}$ & $\begin{array}{l}\text { Code- } \\
\text { Participants }\end{array}$ \\
\hline IT Director & 10 & $\begin{array}{l}\text { Health- } \\
\text { Clinical } \\
\text { Research }\end{array}$ & 750 & $\begin{array}{l}\text { Participant } \\
\text { A }\end{array}$ \\
\hline CIO & 15 & Mining & 50,000 & $\begin{array}{l}\text { Participant } \\
\text { B }\end{array}$ \\
\hline CIO & 20 & $\begin{array}{l}\text { Energy- } \\
\text { Petroleum }\end{array}$ & 3,500 & $\begin{array}{l}\text { Participant } \\
\text { C }\end{array}$ \\
\hline $\begin{array}{l}\text { Business } \\
\text { Development } \\
\text { Manager } \\
\text { (Retail) }\end{array}$ & 26 & Retail & 49,000 & $\begin{array}{l}\text { Participant } \\
\text { D }\end{array}$ \\
\hline $\begin{array}{l}\text { Deputy } \\
\text { Director, IT }\end{array}$ & 25 & & & \\
\hline
\end{tabular}

Semi-structured interviews with open-ended questions were chosen to probe for answers because of their flexibility and ability to obtain rich data from interviews [31]. Face to face interviews were carried out and tape-recorded. In some instances, follow up questions through telephone were carried out to seek clarity.

The Thomas general inductive approach [32] of thematic data analysis employed allows "research findings to emerge from the frequent, dominant or significant themes inherent in raw data, without the restraint imposed by structured methodologies" [32]. To increase dependability of analysis [33] audit trails for three iterations of coding were kept and transcribed notes were sent back to respondents for verification. 


\section{$5 \quad$ Findings and Implications}

Based on the findings of the research, a theoretical model (based on the TOE framework) was developed to explain the relationships between established categories and concepts (Figure 1). The underlying construct of the model is that all three factors affects one another, where the decision to adopt technology innovation is concerned. Hence, the outer link has been made to indicate that any of the technology, organisation and environment factors may affect one another.

For each of the three pillars of the model, three key themes emerged from the data analysis, namely, Business Benefits, Organisation Readiness and System Trust. These three main issues within the TOE aspects influence the decision whether to adopt ERP SaaS or not and are now discussed, supported by quotes from the participants and literature evidence.

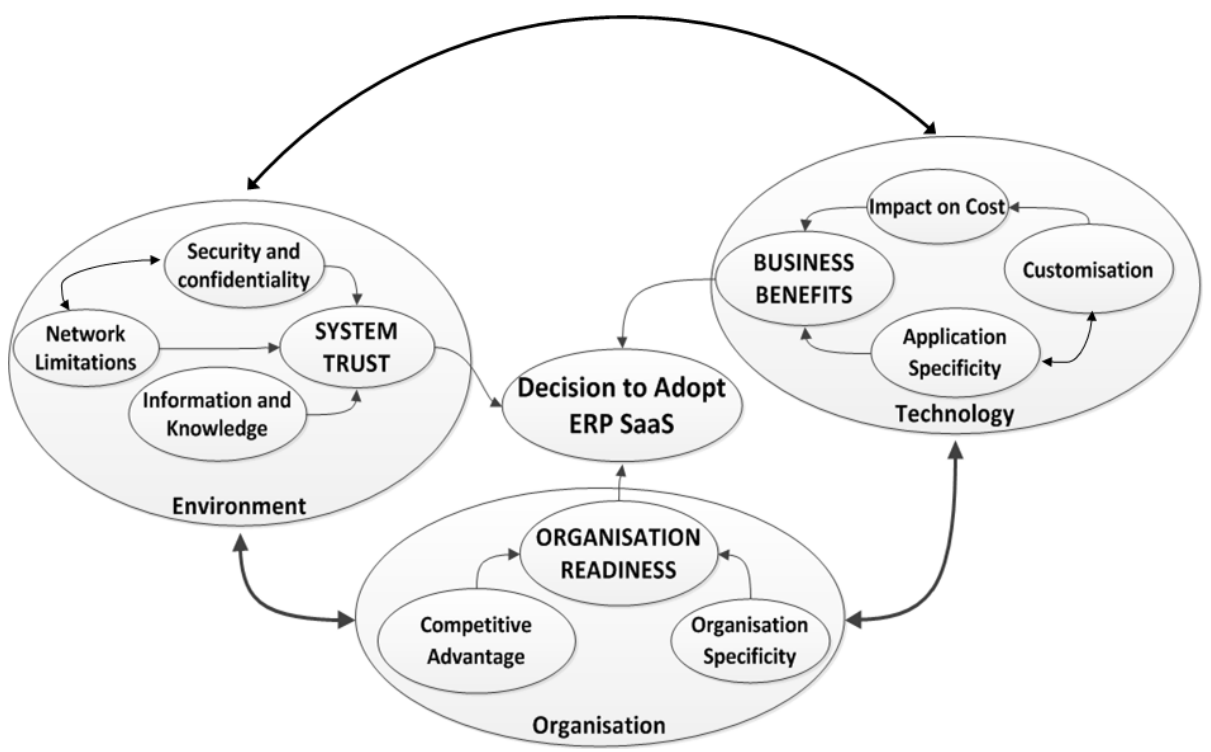

Fig. 1. ERP SaaS adoption model

\subsection{Business Benefits}

Under the technological characteristics of the adoption of ERP SaaS, the perceived business benefits that the clients associate with ERP SaaS have an impact on the overall decision whether to adopt ERP SaaS or not. In regard to business benefits, three main issues emerged from the study.

Cost. The main benefits associated with the adoption of the SaaS model are: low TCO, the subscription pay-as-you go model and ease of implementation [14]. On the other hand ERP systems are associated with high costs of implementation and 
maintenance [1]. The expectation therefore is that the adoption of the ERP implemented on the SaaS model shall neutralise the huge upfront costs associated with ERP systems, and shall also lower the overall cost of ERP systems.

In agreement with findings by Burrel [6] participants perceived that savings in the required upfront implementation costs are seen as a benefit mostly associated with small businesses. Smaller businesses do not have sufficient resources in terms of the technical manpower and funding to manage installed software and therefore could benefit from SaaS without the need to acquire the personnel with requisite skills. "I personally think it could help smaller companies maybe more" (Participant A). Participant D mentioned that ERP-SaaS offered by one prominent ERP software vendor in South Africa targets smaller operations that want to get some elements of ERP running.

The investment in ERP SaaS needs to be justified like any other investment through a clear decision making tool. The clients are of the opinion that they do not have a tool or a yardstick that can be used as a basis for decision making. This uncertainty makes it difficult for the decision makers such as the participants to determine whether ERP SaaS is beneficial in terms of return on investment. Costs and benefits involved in SaaS have been noted as hard to determine [34]. Most importantly, the research participants were very critical of the cost reduction benefits of SaaS, especially for certain organisations with their need for rapid customisation. Yet, the fact that in-house ERP systems are seen as expensive by the participants means that there is an opportunity for ERP SaaS to make headway in any type of organisation regardless of size. That said, the issue of SaaS cost reduction can't be looked at in isolation because of the participant's view that ERP systems demand flexibility that in turn impacts the cost.

Customisation. According to Guo [4], the perceived lack of customisation of ERP SaaS negatively impacts on the adoption of ERP SaaS. This is not only in terms of possible cost increases but also in terms of the flexibility to meet business requirements. ERP systems are not static as rapid customisations are often needed to meet business requirements [1]. In contrast, ERP SaaS is perceived as rigid. The high level of customisation in a rapidly changing environment impacts negatively on the cost reduction benefit, which in turn negatively affects the perceived benefit of ERP SaaS technology.

Yet, SaaS applications are purported to be loosely coupled with configurable components. Clients are able to customise their applications through on-screen clicks without code modifications [12]. This implies that to meet unique requirements of the customers, there may be a need to increase the configurable limit as far as possible towards the client's unique requirements [4].

The view that the respondents hold is that, SaaS is more appropriate for standardised applications that requires little or no customisation. The issue of customisation came out as very important because it is seen as a way to differentiate from the competitors; hence, it was rated highly by the participants.

"Now, the economies of scale and scope, provided the scope is the same, are fantastic in terms of reducing cost. Right? But those services can't give you...., 
there's no differentiating between businesses. You know, it doesn't give you any competitive edge" (Participant B).

Another issue raised about customisation is that which relates to the presence of organisations in different regions or parts of the world. One participant was concerned that the customisation requirements for different regions could complicate ERP SaaS. On analysis, the issue of customisation is seen as a very important inhibiting factor of adopting ERP SaaS. The clients perceive it as being an issue that makes the SaaS model expensive, especially for ERP systems that need to be agile to facilitate a faster response to the changing environment, as well as for facilitating unique processes that gives a company a competitive edge over other competing firms. However, none of the respondents seemed to be aware of the configurability of the SaaS applications, which to some extent addresses the issue of customisation.

Application Specificity. The main issue about application specificity is the fact that ERP is considered too important to run on a SaaS model. The general feeling amongst the research participants is that, although some parts of ERP could be run as ERP $\mathrm{SaaS}$, the model is more appropriate for applications such as Business Intelligence (BI) and Customer Relationship Management (CRM).

Since ERP is seen as a core application, it not considered as appropriate for SaaS model, especially in relation to modules that are considered core. "If you look at ERP systems, you can't just leave it out in the Internet, in a cloud somewhere. It needs to be very secure" (Participant $B$ ).

On addressing the question about which applications are more suitable for the SaaS Model, Participant D was of the opinion that the CRM is more suitable for SaaS. "That is very different to the complexity of an integrated ERP environment...the peripheral functionality that needs quick scaling, quick flexibility, you could probably go and say, let's get that out of the cloud" (Participant D).

Two of the organisations that took part in the study are already using cloud computing, for Spam and Virus filtering and the other one for e-mail. This supports the view that at least for now, the SaaS model is seen as appropriate for standardised and peripheral applications.

The important role ERP system plays in organisations today makes it difficult to hand control over to third parties. One can conclude that the extent to which an application is perceived as being core to the business operations has a negative impact on the adoption of SaaS, and hence ERP SaaS.

\subsection{Organisation Readiness}

The extent to which the business is ready to adopt technological innovation covers organisational factors that influence the adoption or non-adoption decision. Two main issues that were found to affect the organisation's readiness to adopt ERP SaaS are competitive advantage and organisation specificity. 
Competitive Advantage. The competitive advantage here refers to the actual enterprise functions or the processes, and not the type of application itself. The participants were of the opinion that organisation readiness is influenced by the perceived importance of a process/function. If the process is seen as being something that is so important to the organisation in that it provides a competitive edge over other competitors, then such a process/function may negatively influence the decision to adopt. On the other hand processes/functionalise that are not considered core can be readily accepted for adoption of SaaS. Thus ERP modules that are considered less important or not mission critical to the organisation could be easily adopted by such organisations.

"Services that are differentiating to your business, probably software as a service may not work, or maybe it will work but you won't get the economies of scope because it's your specific processes that you don't want to share with other customers or other competitors" (Participant B).

Core processes and functionalities are currently considered as being appropriate only for running in-house because of the reluctance to share the differentiating functionalities with competing firms. It is not so much about the issue of trust as it is the case in application specificity, but rather about the possibility of losing unique identity which is so crucial for businesses to compete successfully.

Organisation Specificity. In addition, the participants view of the size or nature of the organisation influences the adoption of ERP SaaS. The analysis revealed that some of the participants felt that the type of organisation they are in may not be suitable for ERP SaaS adoption. On the other hand, Participant $\mathrm{C}$ asserted that the vendors are probably not looking into ERP SaaS for large organisations.

With regard to the nature of the organisation, there are two main issues raised concerning customisation and confidentiality [28]. As indicated above, organisation with rapid customisation requirements are seen as not being appropriate for ERP SaaS adoption. On the other hand the literature points to certain types of organisations such as those with requirements for confidentiality not readily accepting the adoption of ERP SaaS [25]. This was confirmed by participants:

"How are you going to ensure confidentiality of client's information? We deal with very sensitive information about client's information you know. Medical condition and research issues. How are you just going to leave that in the cloud somewhere?" (Participant A).

Adoption of ERP SaaS amongst big enterprises is impeded by the view that ERP SaaS is appropriate for small operations rather than large corporate. The issue about the need for rapid customisation for enterprises that requires agility and flexibility is also seen as being inappropriate for those organisations. In addition, the nature of organisation with high requirements for confidentiality may negatively impact the decision to adopt ERP SaaS. 


\subsection{System Trust}

System Trust in the context of this paper is the extent to which the organisation expects to benefit from the adoption of ERP SaaS within acceptable levels of security and guarantees in terms of structural assurances and third party guarantees. The structural assurance refers to internet reliability and bandwidth issues. Third party guarantees refer mainly to the assurances that the risk of adopting ERP SaaS shall be mitigated and managed by the vendor. There are three main issues that emerged under the system trust theme: network limitations, security and knowledge.

Network Limitations. The participants felt that the reliability and cost of bandwidth negatively affect the adoption of ERP SaaS in South Africa. The issue of bandwidth did not only apply to the South African environment but in Africa as a whole. SaaS requires a stable and reliable internet connection to access web-based service [9]. Since there are still challenges about broadband access and cost in South Africa and Africa [35],[36] the adoption of ERP SaaS shall be slow compared to other developed countries such as in America and Europe.

Security and Confidentiality. Security and confidentiality strongly influences the trust that the organisation is willing to place on the system [10]. Security was raised as a concern by almost all participants. "Where's the security? How are you going to guarantee security?" (Participant B).

The participants suggested that ERP SaaS vendors have a vested interest in ensuring the security and confidentiality of client's information. But as Participant A mentioned: "What happens when the vendor goes out of business?"

Moreover, since none of the participant organisations use ERP SaaS the concern about security seems to have been caused by the uncertainty about the way in which ERP SaaS operates. This lack of understanding or knowledge about aspects of SaaS could impacts the level of security trust that the users are willing to place on ERP SaaS. In addition, since the vendors have a vested interest in security as it impacts their integrity and reputation, they would probably have more stronger security controls in place than many clients [8].

While maintenance and upgrades were seen by the participants as a benefit of adopting ERP SaaS, others are of the view that it is problematic for the organisation in question. Xin \& Levina [7] have noted that vendors drive future developments of the ERP SaaS system, which makes the users powerless over the control of their upgrades and therefore heavily reliant on the clients on the vendors. This was confirmed by participants: "You lose the ownership and lose the control that you have over the system and you are more manipulated or forced into the direction by the system as when you actually hosting it yourself" (Participant E).

Information and Knowledge. Although the participants seemed to understand what SaaS is and how it works, there is an apparent lack of information about the specifics of ERP SaaS. Information about ERP SaaS may also impact on the organisation 
readiness, since decision making becomes difficult if there is not enough knowledge about the issue at hand.

In addition, there are still "grey areas" in terms of ERP SaaS functionality such as how security works. Participant $\mathrm{C}$ summarised it nicely: "The issue with culture, obviously, needs to be addressed on two levels because there needs to be a clear understanding by everybody in the business, if we were to propose this change, on exactly what Software as a Service entails in the modern business environment today, because I doubt that there is a clear understanding of how it works."

\subsection{Summary of Findings}

Table 2 below highlights factors that affect the adoption of ERP SaaS as well as their impact on the decision to adopt.The environment factors emerged as key in impacting the decision to adopt ERP SaaS in South Africa. Network limitation, security and confidentiality, and the extent of information available to the organisations about ERP SaaS affect the level of trust the clients could place on the system itself. The level of trust placed by the clients on the system as a whole affects the decision whether to adopt ERP SaaS or not. Second to environment issue, are the technology factors, about cost, customisation and application specificity. The current cost of ERP implementation and maintenance positively affect the adoption of ERP SaaS. Yet big organisations do not perceive the SaaS model as being appropriate, especially with respect to their customisation requirements to deliver differentiating products or services. ERP are seen as core applications that are not appropriate for SaaS delivery. On the other hand, the peripheral modules of ERP seem to be favoured with clients for adoption as SaaS.

Surprisingly, the participants did not mention the integration aspects of ERP Software as a Service (SaaS) in determining ERP SaaS. This is despite being one of the most complex and expensive component of SaaS implementation, especially in the enterprise space [12] and with several studies raising integration as one of the factors where SaaS needs to improve [4].

The SaaS model is an emerging business model that completely changes the way software is being delivered to participants [3]. Where ERP SaaS is adopted as opposed to in-house ERP the technology support landscape changes tremendously. This is not restricted to the ICT departments and includes the whole organisation, in terms of culture and required structural readjustments [3]. This implies that ERP SaaS potential clients should consider the likely impact of ERP SaaS adoption on the organisational strategy, Information Technology strategy and governance processes.

The issue of change management and culture was raised by one participant in this research. Another issue that has not been addressed much by empirical research literature is the potential gains in terms of environmental impact of SaaS adoption. 
Table 2. Summary Findings for ERP SaaS Adoption

\begin{tabular}{|c|c|c|}
\hline TOE & Factor & $\begin{array}{l}\text { Impact on Decision to Adopt - } \\
\text { Positive or Negative }\end{array}$ \\
\hline $\begin{array}{l}\text { Technology } \\
\text { Main Theme }\end{array}$ & \multicolumn{2}{|c|}{$\begin{array}{l}\text { Business Benefit - Perceived business benefits shall } \\
\text { influence decision to adopt }\end{array}$} \\
\hline \multirow[t]{3}{*}{ Technology } & \multirow[t]{3}{*}{ Cost } & $\begin{array}{l}\text { Negative for large companies due } \\
\text { to customisation }\end{array}$ \\
\hline & & Positive for small companies \\
\hline & & $\begin{array}{l}\text { Negative for ERP core } \\
\text { applications }\end{array}$ \\
\hline Technology & Customisation & $\begin{array}{l}\text { Negative for rapidly changing } \\
\text { enterprises }\end{array}$ \\
\hline Technology & Application Specifity & $\begin{array}{l}\text { Negative for ERP core } \\
\text { applications }\end{array}$ \\
\hline $\begin{array}{l}\text { Organisation } \\
\text { Main Theme }\end{array}$ & \multicolumn{2}{|c|}{$\begin{array}{l}\text { Organisation Readiness - Organisation's preparedness } \\
\text { to adopt ERP }\end{array}$} \\
\hline Organisation & Competitive Advantage & $\begin{array}{l}\text { Negative for processes seen as } \\
\text { offering competitive advantages }\end{array}$ \\
\hline Organisation & Organisation Specifity & Negative for large enterprises \\
\hline $\begin{array}{l}\text { Environment } \\
\text { Main Theme }\end{array}$ & \multicolumn{2}{|c|}{$\begin{array}{l}\text { System Trust - The level of trust influences the decision } \\
\text { to adopt }\end{array}$} \\
\hline Environment & Network Limitation & Negative for immature \\
\hline Environment & $\begin{array}{l}\text { Information and } \\
\text { Knowledge }\end{array}$ & Negative for system trust \\
\hline Environment & Security & Negative and indifferent \\
\hline Environment & Regulation & $\begin{array}{l}\text { Indifferent (not included in the } \\
\text { theoretical model) }\end{array}$ \\
\hline
\end{tabular}

\section{Conclusion}

The objective of this research was to determine factors that affect the adoption of ERP SaaS in South Africa. Using the TOE framework as a theoretical lens, factors affecting the adoption of ERP SaaS were determined from qualitative data collection and analysis.

In particular, factors relating to the environment emerged as key in deciding on the adoption or non-adoption of ERP SaaS in South Africa with issues around network limitations and security concerns strongly impacting potential adoption. However, as internet technology improves and the cost of bandwidth begins to drop in Africa and South Africa the network issues shall be of a lesser concern.

In regard to issues around the technology, the main factor inhibiting the adoption of ERP SaaS is a concern around customisation and possible costs associated with it. The SaaS model is perceived to be rigid and not allowing for the flexibility required for systems such as ERP. 
Seemingly the evolution has began, with clients starting to adopt peripheral applications through cloud computing. As one participant put it, a transition will occur. "So that's why I'm saying, very excited, think that it's an opportunity and a possibility, but it's going to have to be planned properly and the migration is probably going to be over time. So, what I see here is that there's a transition that will take place from where we are now, to eventually procuring all the services in the cloud."

In general there is a lack of empirical research about Software as a Service (SaaS) in South Africa. This paper has made a first attempt. The research on the same subject focusing on certain industry or type of organisation could also be useful. For instance, the research could focus on the factors affecting adoption of ERP SaaS in Small and Medium Enterprises in South Africa. The results of such research could be consistent and more concrete without generalising amongst participants operating in different industries.

\section{References}

1. Helo, P.: Expectation and reality in ERP implementation: consultant and solution provider perspective. Industrial Management \& Data Systems 108(8), 1045-1059 (2008)

2. Verduyn, M.: Drive Business performance with ERP (2009), http://www.pastel.co.za/Downloads/Newsroom/Enterpreneur August2009.pdf?relid=3657

3. Hofmann, P.: ERP is Dead, Long Live ERP (2008), http://www. computer.org/portal/web/csdl/doi/10.1109/ MIC. 2008.78

4. Guo, P.: A survey of Software as a Service Delivery Paradigm (2009), http://www.cse.tkk.fi/en/publications/B/5/papers/guo_final. paf

5. Benlian, A., Hess, T., Buxmann, P.: Drivers of SaaS- Adoption- An empirical study of different application types. Business \& Information Systems Engineering 1(5), 357-369 (2009)

6. Burrel, C.: New engagement approach in Europe by Fujitsu Services. Fujitsu Science and Technology Journal 45(3) (2009)

7. Xin, M., Levina, N.: Software-as-a-Service Model: Elaborating Client-Side Adoption Factors. In: Boland, R., Limayem, M., Pentland, B. (eds.) Proceedings of the 29th International Conference on Information Systems, Paris, France, December 14-17 (2008)

8. Clair, G.: Software-as-a-Service (SaaS). Put the Focus on the KM/Knowledge Services Core Function. EOS International (2008), http://smr-knowledge.com/wpcontent/uploads / 2010/01/EOS-SaaS-White-Paper-2008.pdf

9. Kaplan, J.: SaaS: Friend or Foe? (2007), http://smrknowledge.com/wpcontent/uploads/2010/01/EOS-SaaS

10. ISACA: Cloud Computing: Business Benefits with Security, governance and assurance perspectives (2009), http://www.isaca.org/Knowledge-Center/Research/ Documents/Cloud-Computing-280ct09-Research.pdf

11. Vaquero, L.M., Cáceres, J., Morán, D.: The Challenge of Service Level Scalability for the Cloud. International Journal of Cloud Applications and Computing 1(1), 34-44 (2011) 
12. Hai, H., Sakoda, S.: SaaS and Integration best practices. Fujutsi Science Technology Journal 45(3), 257-264 (2009)

13. Liao, H., Tao, C.: An anatomy to SaaS Business Mode Based on Internet. International Conference on Management of e-Commerce and e-Government (2008),

http: / / ieeexplore. ieee.org/Xplore/guesthome.jsp

14. Dubey, A., Wagle, D.: Delivering Software as a Service (2007), http: / /www.mckinsey.de/downloads/publikation/mck_on_bt/2007/ mobt_12_Delivering_Software_as_a_Service.pdf

15. Lucas, K.: The State of Enterprise Software Adoption in Europe (2007), http: //www50.sap.com.ezproxy.uct.ac.za/m1/images/global_ data/ERP\%20Lead/UK/Ful1_Doc_Forrester_012907.pdf

16. AberdeenGroup: Trends and Observations (2009), http: / /www . abeerdeen. com

17. Montgomery, N.: Magic Quadrant for ERP for Product-centric midmarket companies. Gartner G00205542 (2010), http://sme.news-sap.com/files/2011/01/ SAP-vol2art5.pdf

18. Kim, W.: Cloud Computing: Today and Tomorrow. Journal of Object Technology 8(1) (January-February 2009)

19. Sahoo, M.: IT Innovations: Evaluate, Strategize, and Invest. IT Professional 11(6), 16-22 (2009)

20. Nitu, M.: Configurability in SaaS (Software as a Service) Applications. In: Proceedings of the 2nd India Software Engineering Conference, Pune, India, February 23-26 (2009)

21. Armbrust, M., Fox, A., Gritthin, R., Joseph, A.D., Katz, R., Konwiski, A., Lee, G., Patterson D., Rabkin, A., Stoica, I., Zaharia, M.: Above the clouds: A Berkeley View of Cloud Computing (2009), http: / / radlab.cs.berkerley . edu

22. Godse, M., Mulik, S.: An approach to selecting Software as a Service (SaaS) Product (2009),

http://doi.ieeecomputersociety.org/10.1109/CLOUD.2009.74

23. Jaekel, M., Bronnert, K., Mewaldt, M.: Software as a Service (SaaS) with Sample Applications (2010), http://www.it-solutions.siemens.com/country/ cee/en/Documents/Publications/at-cc-softwar_PDF_e.pdf

24. Yang, H., Tate, M.: Where are we at with cloud computing? In: Proceedings of the 20th Australasian Conference on Information Systems, ACIS 2009, pp. 807-819 (2009)

25. Mangiuc, D.: Software: From product to service the evolution of a model (2009), http://oeconomica.uab.ro/upload/lucrari/1120091/08.pdf

26. Krishnan, K., Vin, H., Raghavan, V.: TCS and Cloud Computing (2009), http: / /www. indiainfoline.com/Markets/Company/Fundamentals

27. Heart, T., Pliskin, N., Tractinsky, N.: Explaining adoption of remote hosting: A case Study (2008),

http://is2.1se.ac.uk/GlobalSourcing/papers2008/ITP0871.pdf

28. Heart, T.: Empirically Testing a Model for The Intention of Firms to Use Remote Application hosting (2007),

http: / / is2.1se.ac.uk/asp/aspecis/20070065.pdf

29. Nthoiwa, J.: Jumping into the cloud (2010), http://www. itweb.co.za/survey/fujitsusurvey/2009/

30. Klein, H.K., Myers, M.D.: A Set of Principles for Conducting and Evaluating Interpretive Field Studies in Information Systems. MIS Quarterly 23(1), 67-93 (1999)

31. Frankel, R., Devers, K.: Study Design in Qualitative Research - 1: Developing Questions and Assessing Resource Needs (2000),

http: / / www. nova.edu/ssss/QR/Quality.pdf 
32. Thomas, D.R.: A general inductive approach for qualitative data analysis. School of Population Health, University of Auckland, NewZealand (2003)

33. Anfara, V.A., Brown, K.M., Mangione, T.L.: Qualitative Analysis on Stage: Making the Research Process More Public. Educational Researcher, 28-38 (2002)

34. Measuring the return on investment of web application acceleration managed services. IDC, http: / / www. essextec.com/assets / cloud/akamai /idc-waa-roi-wp.pdf

35. Bernabé, F.: Broadband Quality Score III - A global study of broadband quality. Oxford SAID Business School, CISCO (September 2010)

36. Lopez, A.L., Rey, P.: Foreclosing competition through access charges and price discrimination. IESE business school working paper WP - 801 (2009),

http: //papers.ssrn.com/sol3/papers.cfm?abstract_id=1440157 